Ensino, Saúde e Ambiente-V5 (2), pp. 222-233, ago. 2012

\title{
LINGUAGENS VISUAIS E EDUCAÇÃO AMBIENTAL: A BUSCA POR UM NOVO OLHAR
}

\section{VISUAL LANGUAGES AND ENVIRONMENTAL EDUCATION: THE SEARCH FOR A NEW LOOK}

\author{
Lourdes Ferreira $^{1}$ e Rose Mary Latini ${ }^{2}$ \\ ${ }^{1}$ Mestrado Profissional em Ensino de Ciências da Saúde e do Ambiente/UNIPLI e Colégio Pedro II \\ lourdesferreira47@gmail.com \\ ${ }^{2}$ Departamento de Físico-Química/Universidade Federal Fluminense \\ rmlatini@uol.com.br
}

\section{RESUMO}

Este trabalho tem por objetivo fazer um relato analisado da introdução da temática ambiental nas disciplinas de Desenho e Artes, no segundo ciclo do Ensino Fundamental de uma escola pública na cidade do Rio de Janeiro. O tema meio ambiente urbano serviu de base para a proposta, na qual utilizamos como recursos midiáticos a fotografia e o grafite por considerarmos que estas duas linguagens visuais transitam com facilidade no mundo dos jovens estudantes. Utilizamos a observação participante para levantar dados: observações, textos, fotos e desenhos produzidos pelos alunos que foram empregados na análise textual discursiva. Os dados revelaram que o conceito de meio ambiente, inicialmente relacionado a uma visão naturalista, foi abrindo espaço para uma visão mais ampla de ambiente, evidenciando que tais propostas favorecem o estabelecimento de relações entre os saberes e para uma leitura de mundo mais significativa.

Palavras-chave: Educação Ambiental, Linguagens Visuais, Meio Ambiente Urbano

\begin{abstract}
The aim of this work is to make a description analyzed of insert of environmental themes in discipline of Drafting and Arts in second cycle elementary school at a public school in the Rio de Janeiro City. The urban environment was used as theme for proposal and the photography and graphite were used as media resources, because we believe these two visual languages transiting easily in the world of young students. The data: comments, texts, photos and drawings were collected by participant observation method and used in discursive textual analysis. The results show that the environment concept, initially related to a naturalistic vision, was modified to broader view of environment and such proposals promote the establishment of relationships between knowledge and for a world more meaningful reading.
\end{abstract}

Key words: Environmental Education, Visual Languages, Urban Environment

\section{INTRODUÇÃO}

$\mathrm{O}$ ato de educar pressupõe a idéia de que a relação entre educador e educando não se limita à simples transmissão de conhecimentos, mas a uma relação baseada na cumplicidade própria daqueles que entendem o conhecimento como uma rede de saberes complexa e instigante, apontando que a essência da educação deve ser a “abertura da mente para receber o novo.” (MORIN, 2002, p. 72) 
É baseado na ampliação das fronteiras entre as diferentes áreas do conhecimento e na busca pelo desenvolvimento de uma leitura crítica da realidade que os PCN sugeriram a inclusão dos Temas Transversais no sistema nacional de ensino. A articulação entre os temas propostos e as demais áreas do conhecimento deve considerar a relevância do tema para o contexto local e o grau de aprofundamento das questões, mas, sobretudo, que as atividades desenvolvidas no espaço escolar tenham como objetivo a construção da cidadania. (BRASIL, 1998a)

Ao incluir o Meio Ambiente como um dos temas propostos, os PCN buscam promover a formação de "cidadãos conscientes", críticos e "comprometidos com a vida", através do fortalecimento de uma nova concepção a respeito das relações do homem com a natureza e com as instâncias política, social e cultural. (BRASIL, 1998b, pp. 176 e 187).

Mas, como inserir a temática ambiental em sala de aula? Quais pressupostos teórico-metodológicos orientam sua práxis? Como transversalizar a temática nos conteúdos das disciplinas? Ainda de acordo com os PCN, "a perspectiva ambiental deve remeter os alunos à reflexão sobre os problemas que afetam a sua vida" e acrescenta que para que este "aprendizado seja significativo os alunos precisam estabelecer ligações entre o que aprendem e a sua realidade cotidiana" (1998b, pp.189-190)

De acordo com Tozoni-Reis (2005), a criação de propostas criativas e diversificadas que relacione a teoria à prática não pode perder de vista sua importância tanto social quanto científica. Para Carvalho (2004, p. 19), a parceria entre a educação ambiental e o "pensamento crítico" potencializa a ação educativa voltada para a formação de "indivíduos e grupos sociais capazes de identificar, problematizar e agir em relação às questões socioambientais".

Neste sentido, nos questionamos de que forma poderíamos introduzir a temática ambiental nos programas de Desenho e Arte no Ensino Fundamental. A cultura visual, tão presente em nossos dias, demonstra que o Desenho não se limita à representação tradicional dos elementos geométricos ou à resolução gráfica de problemas, sendo, especialmente, um conjunto de saberes que dialoga com outras áreas, quer sejam científicas, tecnológicas ou humanas. Do mesmo modo, os PCN consideram a Arte como uma forma de expressão resultante das interrelações entre as "percepções presentes em diversas práticas e conhecimentos humanos.” (BRASIL, 1999, p. 93).

Destacamos que tanto o Desenho quanto a Arte são linguagens que podem contribuir para práticas educativas interdisciplinares e acessíveis à inclusão de recursos 
e temas contemporâneos, entre eles os temas transversais, como propõem os PCN. Desse modo, pensamos no espaço urbano como um tema propício para cumprir estes propósitos. Espaço urbano entendido como a realidade concreta (FREIRE, 2002), ou mais precisamente, a maneira como cada um percebe e analisa os diferentes fatores que atuam no complexo sistema social.

Assim, o objetivo deste trabalho é fazer um relato analisado da introdução da temática ambiental nas disciplinas de Desenho e Artes, no segundo ciclo do Ensino Fundamental, em uma escola pública na cidade do Rio de Janeiro.

Procuramos adotar uma abordagem interdisciplinar, na qual o tema meio ambiente urbano se apropriou, em determinados momentos, das linguagens visuais matéria prima das disciplinas Desenho e Artes - como forma de expressar a concepção que os sujeitos da pesquisa possuem sobre o assunto. Com relação ao Desenho, um dos seus conteúdos é o estudo da perspectiva cônica que se caracteriza pela representação dos objetos e do espaço do mesmo modo como são vistos pelo observador. Por outro lado, as intervenções no espaço urbano provocadas pelo grafite ${ }^{1}$ nos levaram a associar as duas linguagens - a perspectiva e o grafite -, já que ambas possuem o espaço real como referencial.

A opção pelo espaço urbano tem, também, como referencial teórico os PCN. O documento evidencia a importância de se aprofundar as questões ambientais a partir da percepção que o grupo possui de seu ambiente (BRASIL, 1998a).

Compartilhando da mesma visão apresentada pelos PCN, Reigota (2010) considera que em uma prática educativa envolvida com a questão ambiental é necessário que o grupo tenha uma clara concepção quanto ao significado do conceito meio ambiente. Diante disso adotamos a definição de meio ambiente proposta pelo autor, tendo em vista o modo abrangente como ele trata o tema.

\footnotetext{
O lugar determinado ou percebido, onde os elementos naturais e sociais estão em relações dinâmicas e em interação. Essas relações implicam processos de criação cultural e tecnológica e processos históricos e sociais de transformação do meio natural e construído. (op. cit., p. 14)
}

O tema gerador 'meio ambiente urbano' teve por base os princípios enunciados por Layrargues (2008, pp. 121-122), uma vez que, para o autor, a prática educativa apoiada em tema gerador possibilita ir além da visão estritamente ecológica da questão

${ }^{1} \mathrm{O}$ termo grafite ou grafito deriva da palavra italiana graffiti (plural de graffito) e significa inscrição ou desenho toscamente riscado sobre rochas ou paredes em épocas antigas. (GITAHY,C. O que é graffiti. São Paulo: Brasiliense, 2002, p. 13) 
ambiental. O conceito de meio ambiente é percebido, então, como uma rede de articulações sociais, culturais, políticas, econômicas e éticas, "inserida em uma cadeia sistêmica de causa e efeito".

Para realizar este trabalho adotamos a abordagem qualitativa (LÜDKE e ANDRÉ, 2003), já que temos como proposta investigar aspectos de um determinado contexto social, ou seja, a presença de significados, representações e valores próprios do grupo. A observação participante foi o método utilizado para coleta de dados e que, segundo as autoras, permite que o pesquisador se aproxime dos sujeitos da pesquisa de modo a "tentar apreender a sua visão de mundo, isto é, o significado que eles atribuem à realidade que os cerca e as suas próprias ações”. (op. cit. p. 26)

As falas, os textos, as fotografias e os desenhos produzidos pelos alunos foram os dados utilizados na análise textual discursiva (MORAES, 2003). De acordo com o mesmo autor, os textos são compreendidos "como produções lingüísticas, referentes a determinado fenômeno e originadas em um determinado tempo (...) são significantes dos quais são construídos significados em relação aos fenômenos investigados” (op. cit., p. 194).

Para Machado (2001 apud CIAVATTA e ALVES, 2008, p.12) vivemos em uma sociedade eminentemente imagética que "aprendeu não apenas a conviver com as imagens, mas também a pensar com as imagens." Diante disso, é possível supor que as informações sobre algo real ou imaginário, além de poderem ser expressas através de linguagens verbais, têm nas linguagens não verbais um canal atual e com forte apelo junto à sociedade.

\section{RELATO DA EXPERIÊNCIA}

Iniciamos o trabalho esclarecendo aos alunos os objetivos deste estudo. Esse primeiro contato é extremamente importante para que haja cooperação entre os sujeitos e se estabeleça uma parceria aberta ao diálogo. (NETO, 1993, p. 55).

A fim de conhecer a percepção do grupo sobre o significado de meio ambiente pedimos aos alunos que fotografassem um local, um detalhe, algo que refletisse o seu entendimento sobre o tema. De posse do material fotográfico montamos, em outro momento, uma apresentação. Antes da exposição solicitamos aos alunos que expressassem a idéia de meio ambiente utilizando uma palavra. As palavras que mais apareceram foram "mata, mar, flora, fauna, rio, ecossistema, animais, paisagem, onda, jardins", demonstrando que o conceito de meio ambiente estava relacionado apenas aos aspectos naturais. 
Assim como as falas, a maioria das fotografias revelou um conceito de ambiente naturalizado, onde apenas os aspectos relacionados ao local onde vivem e aos "elementos circundantes" (água, solo, ar) são ressaltados e desconsideram aspectos que evidenciam o "caráter multifacetado e existencial" da problemática ambiental. (REIGOTA, 2010, p. 76)
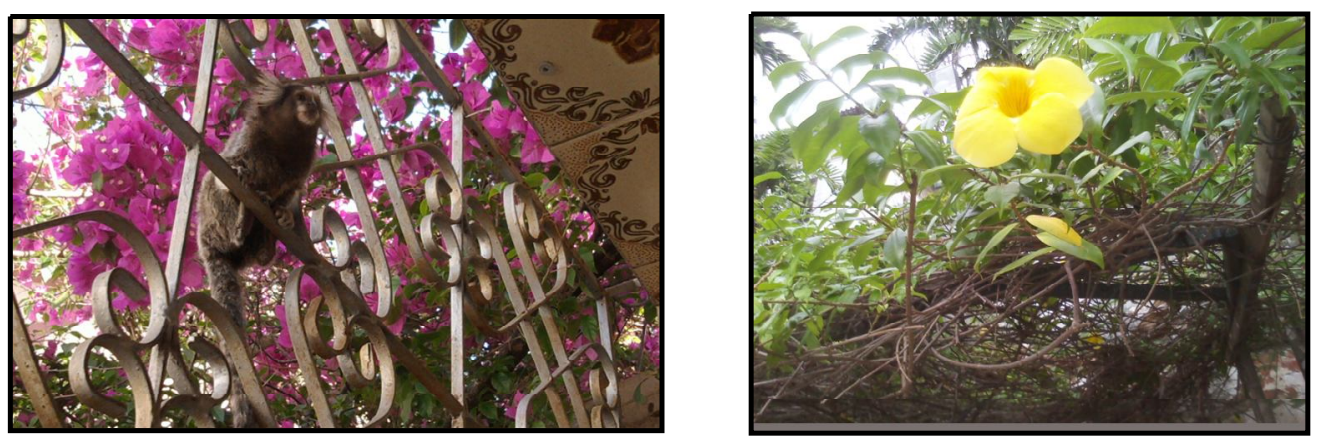

Figura 1: Fotos apresentadas pelos alunos retratando suas concepções de meio ambiente

Paulo Freire vê a educação como um instrumento capaz de colaborar com o indivíduo na "indispensável organização reflexiva do pensamento", acrescentando ser necessário disponibilizar os meios capazes de "superar a captação mágica ou ingênua de sua realidade, por uma dominantemente crítica." (FREIRE, 2002, p. 114).

Durante a exposição das fotos, seus autores explicavam o porquê de suas escolhas e os demais alunos acrescentavam as observações que considerassem pertinentes. Neste momento, foram apontadas questões como "desmatamento, lixo e poluição" decorrentes de imagens que retratavam zonas desmatadas e a produção de lixo.

"Nós produzimos o lixo. Não consigo imaginar o meio ambiente sem lixo."

"A foto é para mostrar que estão desmatando aquela área para a construção de avenida."

"Nem sempre o lixo está na lixeira, ele ocupa os espaços. Mas no meio ambiente natural não tem essa poluição, depende de onde estamos."

Segundo Vigotski (1996, p. 53), os conceitos já estabelecidos estão inevitavelmente vinculados à vida social, o que nos remete à influência da mídia que, com frequência, relaciona os três itens - desmatamento, lixo e poluição - à preservação do meio ambiente e aos trabalhos de viés fortemente conservador desenvolvidos na maioria das escolas brasileiras (TRAJBER e MENDONÇA, 2006)

Para aprofundar nossas reflexões sobre a dinâmica homem/sociedade/natureza utilizamos um texto de Reigota (2010, p. 15) no qual o autor apresenta suas considerações a respeito das transformações nas relações dos indivíduos com o "meio 
natural e construído." Com o texto de Reigota, procuramos mostrar que o conceito de meio ambiente envolve "elementos naturais e sociais" em constante relação.

Foram mostradas, ainda, fotos do Rio contemporâneo e do Rio do século XX possibilitando avaliar de modo mais crítico como a apropriação indiscriminada do espaço afeta a vida humana em diferentes níveis, bem como o papel das instâncias político-econômicas nesse processo.

Os PCN deixam claro que ao abordarmos a relação do homem com o contexto local é possível que o aluno compreenda que as questões ambientais envolvem todos os segmentos da sociedade. O documento acrescenta:

\begin{abstract}
ao estudar as transformações da paisagem (...) é interessante interpretar suas consequiências para a dinâmica ambiental local. Porém, ao incluir, nesse estudo, os interesses de grupos, os conflitos sociais e os aspectos econômicos no interior dos quais foram definidas e implementadas essas atuações, possibilita-se aos alunos ampliar seu universo de compreensão sobre cada forma específica de intervenção ambiental. (BRASIL, 1998b, p. 212)
\end{abstract}

A mostra comparativa das imagens do Rio de Janeiro tornou-se um momento rico em observações e participação. Entre curiosos e surpresos, os alunos perceberam a apropriação de áreas urbanas em diferentes pontos da cidade. Os comentários do grupo envolveram temas como: especulação imobiliária, lucro das construtoras, falta de fiscalização. Nesse momento, a visão naturalista abre espaço para os aspectos sociais.

Posteriormente, foram discutidas três questões: $\mathrm{O}$ que é ter qualidade de vida? O que você entende por meio ambiente urbano? Que associações você faz entre qualidade de vida e meio ambiente urbano?

Para os alunos, ter qualidade de vida está associado ao "lazer, condições básicas de sobrevivência, dinheiro, alimentação, moradia, trabalho, interação com as pessoas, saúde, educação, meio ambiente limpo e organizado, sem preconceitos, igualdade,". A palavra interação, cujo significado era desconhecido quando da leitura do texto de Reigota, passa agora a fazer parte do vocabulário do grupo.

Com relação à pergunta: o que você entende por meio ambiente urbano, apresentamos algumas respostas: "lazer, ambiente modificado, poluição, barulho, tecnologia, integração entre as pessoas, trânsito, capitalismo, excesso de pessoas, violência, corrupção, desigualdade”. As respostas ressaltam as características do espaço urbano em uma espécie de inventário da cidade, no qual o lazer foi o primeiro item a ser citado. Segundo Vogel et al (1995, p.116), a cidade torna-se, para o olhar do 
jovem, um "conjunto de lugares e eventos divertidos para desfrutar e curtir" contrapondo-se à rotina e às atividades trabalhosas.

Ao mencionarem os aspectos negativos (barulho, violência, poluição) os jovens estão, de certo modo, avaliando e criticando o espaço urbano ou, talvez, buscando "sensibilizar alguém capaz de resolver as deficiências." (op. cit., p. 97). Mas, apesar das críticas, sobressai o lado lúdico da cidade, aquele que oferece diversão e prazer.

Quanto à terceira pergunta: que relações você faz entre qualidade de vida e meio ambiente urbano, alguns alunos precisaram fazer um paralelo com o espaço rural para explicarem seus conceitos sobre a questão. O dinheiro, que já havia sido mencionado quando da primeira pergunta, aparece aqui de modo mais claro. Eis algumas respostas:

"Aqui na cidade você pode ter uma vida boa, mas você precisa ter um pouco de dinheiro. No campo com um pouquinho de dinheiro, você pode ter casa, uma coisa pequena, mais barata. Aqui na cidade é muito mais caro."

"Você tendo dinheiro é mais bem visto na sociedade, tem mais opções."

"O dinheiro vai me dar condições de lazer, saúde, moradia, educação e alimentação."

"A conclusão que nós tiramos é que o dinheiro gera bastante coisas, sem dinheiro, nada. Porque preparo não é tudo."

Apesar de compreenderem o meio ambiente como sendo um espaço social, os alunos demonstraram possuir uma visão individualista, já que vinculam qualidade de vida à estabilidade financeira pessoal, desconsiderando a sociedade como um todo, privilegiando o individual sobre o coletivo. Entretanto, isto é uma forte característica das pessoas que vivem em grandes centros urbanos, como é o caso dos sujeitos da pesquisa.

De acordo com Carvalho (2004, p. 20), indivíduo e sociedade "só fazem sentido se pensados em relação", não havendo a possibilidade, dentro de uma perspectiva ambiental crítica, de hierarquizar as ações e relações entre os indivíduos, os grupos sociais e o ambiente. As mudanças que se fazem necessárias no sistema macro-social só podem ocorrer se houver a devida articulação entre essas três dimensões.

Por outro lado, vivemos em uma sociedade na qual o estímulo ao consumo se dá de modo intenso e constante o que justificaria, também, a correlação entre ter qualidade de vida e a aquisição de bens enunciada pelos alunos. Não podemos esquecer que o grupo é formado por jovens de classe média e uma das características desse nível social é o valor dado ao dinheiro como meio de ascensão social.

Segundo Bakhtin (1997, p. 301), o gênero de um discurso é influenciado tanto pelas peculiaridades do grupo quanto pela temática, dados que, portanto, explicariam as 
observações dos alunos quanto à importância do dinheiro. Apresentamos, ainda, outras falas:

"Aqui tem mais pessoas, mais coisas prá fazer, tem mais tecnologia e lá (no campo) você tem que ler livro e tal."

"Aqui tem mais violência, aqui as pessoas morrem mais por violência. Lá no campo eles morrem mais de coisas naturais (...). É bem mais perigoso aqui."

Destacamos na primeira frase as palavras "tem que ler livro e tal" por considerar que elas denotam uma associação entre leitura e falta do que fazer, além de uma visão idealizada sobre a vida no espaço urbano.

Vogel et al (1995, p. 78) fazem uma interessante análise sobre a vida na cidade. Os aspectos negativos como violência, poluição, corrupção podem ter para os alunos o significado de aventura, "riscos e imprevistos" dando à vida na cidade um enfoque dinâmico quando comparada à vida no campo. Assim, "os perigos, especialmente vistos a distância, podem transformar-se em simples promessas de aventuras". Os autores acrescentam que a cidade do Rio de Janeiro é um lugar que oferece inúmeras atrações (parques, cinemas, teatros, praias, centros comerciais), exercendo, portanto, certo fascínio para os jovens.

Considerando que em nosso último encontro discutimos qualidade de vida e meio ambiente urbano, retornamos aos temas a partir da leitura dos artigos da Constituição Federal que tratam dos objetivos fundamentais e das competências dos três níveis do poder público. Foram mostradas, também, imagens com as quais é possível perceber como o Estado atende de modo desigual às demandas da sociedade, contrariando o que está escrito na lei. As questões abordadas foram: educação, moradia, saneamento, lazer, saúde e transporte. Durante a apresentação, o grupo mencionou o que tem sido assunto recorrente na mídia: a ausência do Estado na saúde pública, a desumanização do atendimento médico tanto no âmbito público quanto no privado, a falta de cuidado no descarte do lixo, a qualidade do ensino público, o papel da educação na conscientização dos indivíduos.

De acordo com Bakhtin (1997, p 316), o modo como nos expressamos sobre determinado tema está "repleto de ecos e lembranças" de outros enunciados que podem retornar na íntegra ou através de palavras isoladas. Isso talvez explique o discurso dos alunos ao utilizarem os termos que, com certa frequência, são ditos ou lidos em nosso dia a dia e, sem que notemos, passam a fazer parte do nosso ideário.

Em seguida, os alunos elaboraram em grupo algumas considerações sobre as relações do homem com o meio ambiente. Obtivemos pequenos textos, alguns com 
abordagens ainda essencialmente naturalistas, enquanto que outros incluíram os aspectos sociais em suas reflexões. O valor do dinheiro reaparece, porém agora, também, com a conotação de lucro. Eis alguns trechos:

"O homem tem sido desrespeitoso com o meio ambiente em geral, ocorrendo injustiça (...), egoísmo e desigualdade entre as pessoas (...). Ganância, colocando o dinheiro em primeiro lugar."

"O homem está modificando o meio ambiente sem pensar nas consequências que essas modificações podem causar na fauna e na flora. O homem de hoje em dia pensa apenas no lucro."

"Essas relações deveriam ser em vez de alterar e 'maltratar' o meio onde vivemos, melhorar cada vez mais nossas relações uns com os outros, com justiça, saúde, educação, ética."

Segundo Meyer (1991, p. 43), não estamos habituados a observar e, principalmente, avaliar as mudanças ocorridas em nosso contexto imediato, uma vez que a rotina, o convívio diário com os mesmos "fatos, fenômenos e pessoas" acaba por tornar corriqueira qualquer alteração no ambiente. Embora, a responsabilidade pelas alterações ambientais seja atribuída a um homem genérico (LOUREIRO, 2004), percebemos que houve uma ampliação na concepção dos alunos a respeito das relações entre os indivíduos e o meio ambiente.

No encontro seguinte analisamos as diferenças entre grafite e pichação bem como as penalidades legais impostas a quem danifica o patrimônio cultural. Isto serviu de base para a mostra de imagens nas quais aparecem 'inscrições' feitas nas paredes da sala de aula. Mas, foi, principalmente, um momento de reflexão sobre a preservação do espaço escolar e a ocorrência de conflitos entre as turmas quanto aos danos causados, pelos alunos, nos murais. A partir do espaço escolar avaliamos o modo como agimos no trato com o espaço urbano.

Com foco no grafite, apresentamos algumas reproduções de criações artísticas que utilizam as paredes como suporte, abrangendo desde o período paleolítico até os dias atuais. Diante de cada imagem, comentávamos as diferenças formais e a intenção de cada produção tendo em vista o momento histórico em que se inserem.

A seguir, foi proposto aos alunos a criação, em grupo, de um desenho que representasse criticamente, ou como uma denúncia, um dos temas ambientais discutidos em sala de aula. O desenho deveria ter as características do grafite e o recurso utilizado foi um programa computacional que simula as condições em que se realiza essa linguagem visual. 


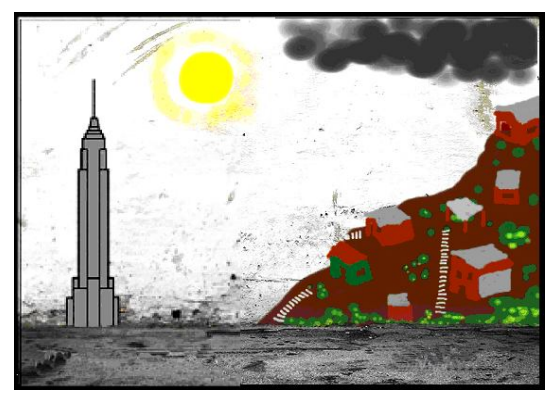

Desigualdade

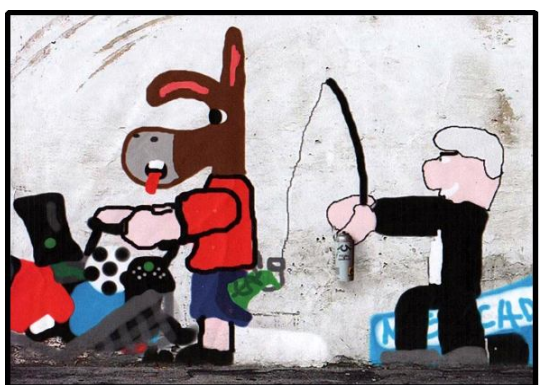

Capitalismo: alguém ganha à custa da sociedade

Figura 2: Grafites produzidos pelos alunos

Os desenhos apontaram questões como desigualdade social, aquecimento global, ética, capitalismo, destruição das florestas, corrupção e consumo desenfreado. A figura 2 exibe alguns desses desenhos, que no encontro posterior, foram todos mostrados para a turma e cada grupo expôs as intenções de suas criações.

Com o intuito de avaliar a apropriação dos conceitos construídos ao longo do trabalho, pedimos que cada aluno escrevesse sua compreensão sobre o conceito de meio ambiente. $\mathrm{O}$ resultado foi agora mais expressivo no que se refere à inclusão dos fatores sociais e políticos na dinâmica ambiental. Entretanto, ainda permanece, em alguns alunos, uma visão restrita à concepção ecológica do meio ambiente.

"Meio ambiente é o espaço onde vivemos. Envolve questões físicas, ambientais, urbanas e também questões sociais e políticas."

"Eu defino meio ambiente como tudo aquilo em que vivemos e não só como natureza, que é o que quase todo cidadão pensa."

"Meio ambiente é tudo que está na nossa volta, desde floresta, mar e etc., até o lixo."

"Lugar onde nós vivemos, lugar que temos que cuidar, não desmatar, salvar animais e etc".

No mesmo momento, pedimos, também, uma avaliação individual de todo o processo, apontando os aspectos positivos e negativos dos nossos encontros. As apreciações revelaram a importância de abrir espaço na sala de aula para a troca de opiniões o que, segundo Paulo Freire (2002, p. 98), seria o papel da educação: levar o homem a manter um "diálogo constante com o outro. Que predispusesse a constantes revisões. À análise crítica de seus achados."

"Eu aprendi muito sobre o meio ambiente e com certeza cresci como pessoa, pois aprendi a ouvir a opinião dos outros mesmo que não fossem a mesma que as minhas."

"Nos fez refletir sobre como estão as coisas ao nosso redor, (...) se queremos mudar ou manter isso. No momento todos participam, mas, daqui a algum tempo todos vão esquecer. Acho que deveríamos continuar com esses encontros e debates ao longo das séries." 
"Graças às aulas passei a ter uma idéia diferente sobre o meio ambiente. Passei a definir como uma coisa muito maior do que achava antes."

Fica evidente a importância dada ao fato de se poder falar e ouvir, mas, sobretudo, porque é possível reformular conceitos e ampliar o conhecimento. Para Vigotski (2011), à medida que temos uma nova visão das coisas adquirimos a capacidade de manipular e dominar esses novos conceitos, tornando nossa percepção mais generalizante.

O autor (1996, pp. 60 - 64) dá especial atenção ao período da adolescência afirmando que a formação de conceitos nessa faixa etária não é apenas a continuação de um processo iniciado na infância, mas sim "uma nova atividade intelectual (...) que se diferencia das anteriores tanto por sua composição e estrutura como pelo modo como atua." Essa nova maneira de pensar dá origem a novas condutas uma vez que "o pensamento em conceitos abre para o adolescente o mundo da consciência social objetiva."

\section{CONSIDERAÇÕES FINAIS}

A escola, espaço por excelência do conhecimento, tem muito a contribuir para o desenvolvimento nos jovens de uma postura crítica frente às questões ambientais e à realidade concreta. Para tanto, é preciso que a educação reformule seus objetivos e métodos, não se limitando à transmissão de conteúdos pré-estabelecidos.

Reconhecemos as dificuldades encontradas no cenário escolar brasileiro, mas como professores não podemos nos omitir de nosso papel como mediadores na construção de valores humanos e no incentivo ao desenvolvimento de uma percepção mais sensível quanto à relação indivíduo/meio ambiente, reconhecendo que ambos constituem um sistema complexo e dialógico.

Entretanto, prevalece a constatação de que é possível construir parcerias, de propor caminhos alternativos e criativos para a prática educativa. Esperamos que as ideias aqui apresentadas ultrapassem o espaço/tempo desta pesquisa, estimulando a contínua busca por uma educação que privilegie aprendizagens mais significativas para os jovens. Aprendizagem significativa entendida como um processo que correlacione os saberes já constituídos com experiências que possam produzir novos entendimentos sobre a questão ambiental.

\section{REFERÊNCIAS BIBLIOGRÁFICAS}

BAKHTIN, M. Estética da criação verbal. $2^{a}$ edição. São Paulo: Martins Fontes, 1997 BRASIL. Ministério da Educação. Secretaria de Educação Fundamental. Parâmetros Curriculares Nacionais: temas transversais para o terceiro e quarto ciclos. Brasília: 
MEC/SEF, 1998a. Disponível em www.portal.mec.gov.br/seb/arquivos/pdf/ ttransversais.pdf Acesso em: 22/072010

. Ministério da Educação. Secretaria de Educação Fundamental. Parâmetros

Curriculares Nacionais: Meio Ambiente. Brasília: MEC/SEF, 1998b. Disponível em www.portal.mec.gov.br/seb/arquivos/pdf/meioambiente.pdf. Acesso em: 22/07/2010. . Ministério da Educação. Secretaria de Educação Média e Tecnológica.

Parâmetros Curriculares Nacionais: Linguagens, Códigos e suas Tecnologias. Brasília: MEC/Secretaria de Educação Média e Tecnológica, 1999.

CARVALHO, I. C. M. Educação Ambiental Crítica: nomes e endereçamentos da educação. In LAYRARGUES,P. P. (Org.) Identidades da educação ambiental brasileira. Brasília: Ministério do Meio Ambiente, 2004. p 13- 24 CIAVATTA, M. e ALVES, N. A leitura de imagens na pesquisa social: História, Comunicação e Educação. $2^{\underline{a}}$ ed. São Paulo: Cortez, 2008.

FREIRE, P. Educação como prática da liberdade. $26^{\underline{a}}$ ed. São Paulo: Paz e Terra, 2002.

LAYRARGUES, P. P. A resolução de problemas ambientais locais deve ser um temagerador ou a atividade-fim da educação ambiental? In REIGOTA, M. Verde

Cotidiano: o meio ambiente em discussão. $3^{\underline{a}}$ ed. Petrópolis:DP et $a l ., 2008$. p.113127.

LOUREIRO, C. F. B. Educação ambiental transformadora. In LAYRARGUES,P. P. (Org.) Identidades da educação ambiental brasileira. Brasília: Ministério do Meio Ambiente, 2004. p.65 - 84

LÜDKE, M. e ANDRÉ, M. E. D. A. Pesquisa em Educação: abordagens qualitativas. $6^{\underline{a}}$ reimpressão. São Paulo: EPU, 2003

MEYER, M. A. A. Educação Ambiental: uma proposta pedagógica. Em aberto, Brasília, v.10, n. 49, jan./mar. 1991, p.41-6. Disponível em www.inep.gov.br/ index.php/emaberto/article/ viewfile/758/679. Acesso em abril/2011.

MORAES, R. Uma tempestade de luz: a compreensão possibilitada pela análise textual discursiva. Ciência e Educação, v.9, n.2, p. 191- 211, 2003. Disponível em www.scielo.br/pdf/ciedu/v9n2/04. Acesso em 08.02.2012

MORIN, E. Os sete saberes necessários à Educação do futuro. $6^{\underline{a}}$ ed.São Paulo: Cortez, 2002.

NETO, O. C. O trabalho de campo como descoberta e criação. In MINAYO, M. C. S. (Org.) Pesquisa Social. Teoria, método e criatividade. $21^{\underline{a}}$ edição. Petrópolis: Vozes, 1993. p. $51-66$.

REIGOTA, M. Meio Ambiente e Representação Social. $8^{\text {a }}$ ed. São Paulo: Cortez, 2010 .

TOZONI-REIS, M. F. C. A construção coletiva do conhecimento e a pesquisa-açãoparticipativa: compromisso e desafios. III Encontro de Pesquisa em Educação Ambiental - EPEA. Ribeirão Preto, 2005.

TRAJBER, R; MENDONÇA, P. R. Educação na diversidade: o que fazem as escolas que dizem que fazem educação ambiental - Brasília: Secretaria de Educação Continuada, Alfabetização e Diversidade, 256 p.: il. - Coleção Educação para Todos. Série Avaliação, n. 6, v. 23. 2006. Disponível em http://unesdoc.unesco.org/images/0015/001545/154576por.pdf. Acesso em julho de 2010.

VIGOTSKI, L. S. Pensamento e Linguagem. 4a ed. São Paulo: Martins Fontes, 2011. . Psicologia Infantil. Obras escogidas, vol. IV. Madrid: Visor, 1996

VOGEL, A; VOGEL, V.L.O.; LEITÃO, G.E.A. Como as crianças vêem a cidade. Rio de Janeiro: Pallas, 1995 